\title{
Optimization and validation of a chromatographic methodology for the quantification of PAHs in drinking water samples
}

\author{
A. S. Cardoso, S. A. Feliciano, M. H. Rebelo, S. S. José \& C. Reis \\ Enviromental Health Department, \\ Instituto Nacional de Saúde Dr. Ricardo Jorge, Lisbon, Portugal
}

\begin{abstract}
Polycyclic aromatic hydrocarbons (PAHs) are one of the most important persistent organic toxic micropollutants present in water. These compounds are essentially known for their carcinogenic, mutagenic and genotoxic properties, especially the PAHs containing four or more aromatic rings.

The determination of these compounds in water is a challenging situation, making it necessary to develop specific methods with very low detection limits.

This work describes the optimization and validation of a methodology for the determination of the five PAHs proposed in the Portuguese legislation, using a solid phase extraction technique followed by a reverse-phase high performance liquid chromatography with fluorescence detection: benzo[b]fluoranthene, benzo[k]fluoranthene, benzo[ghi]perylene, indene[1,2,3-cd]pyrene and benzo[a]pyrene.

The performance of the methodology was tested in terms of linearity, limits of detection and quantification, trueness, repeatability and intermediate precision, following the recommendations of the international standard ISO/IEC 17025. The method showed good linearity for the tested concentration range, with limits of detection less than $0.29 \mathrm{ng} / \mathrm{L}$ for all the PAHs. Analytical recoveries, repeatability and intermediate precision were calculated in ultra-pure, bottled and tap water, with recoveries values ranging from 80 to $110 \%$, repeatability and precision RSD values less than $15 \%$.

The methodology was applied to real water samples, fifty water springs from Sintra municipality. In the samples analyzed, PAHs were detected under the limits proposed by the legislation.

Keywords: drinking water, polycyclic aromatic hydrocarbons, SPE-HPLC-FLD, validation, Natural spring waters.
\end{abstract}




\section{Introduction}

Polycyclic aromatic hydrocarbons (PAHs) are widespread persistent contaminants in the environment. They belong to a very large group of organic compounds that are formed in the incomplete combustion of organic matter, being released directly to the atmosphere through burning and reaching latter on other matrices, such as water and food [1-3].

PAHs are essentially known for their carcinogenic, mutagenic and genotoxic properties, especially the PAHs containing four or more aromatic rings [4-6]. According to the World Health Organization (WHO), benzo(a)pyrene is the most toxic compound, being classified as carcinogenic to animals and probable human carcinogen, in IARC Monographs. Recent studies lead scientists to believe that some PAHs and their metabolites are endocrine disrupters $[7,8]$. Attending to the possible biological effects on human health and the enormous negative impact in the environment, it became imperative to develop methods for the detection and quantification of these compounds in water samples at trace levels.

The quantification of PAHs in water matrices is a challenging situation, since they are found as complex mixtures and in trace levels, which implies the development of a specific method with very low detection levels [3,9].

The Portuguese legislation for water for human consumption (DL 243/2001) and European Directive 98/33/EC proposes the determination of four PAHs: benzo(b)fluoranthene $(\mathrm{BbF})$, benzo $(\mathrm{k})$ fluoranthene $(\mathrm{BkF})$, benzo(ghi)perylene (BghiP), indeno(1,2,3-cd)pyrene (IcdP) and limits the total concentration to 0.10 $\mu \mathrm{g} / \mathrm{L}$; and benzo(a)pyrene (BaP) limited to the maximum concentration of 0.010 $\mu \mathrm{g} / \mathrm{L}$. The referred PAHs have five and six aromatic rings and are indicators of drinking water quality.

Several reference methods have been proposed for the analysis of PAHs in water samples, the most common being HPLC-UV, HPLC-FLD, HPLC-DAD [3,10-20], GC-MS and GC-FID [1,2,21-29].

The extraction and preconcentration of PAHs from water samples is described in the EPA methods (US Environmental Protection Agency) and in Standard Methods for the Examination of Water and Wastewater, using liquid-liquid extraction (LLE) and solid-phase extraction (SPE), which are methods widely used by several authors [1-3,13-15,19,27-28]. Nevertheless other methods such as solid-phase microextraction (SPME) [16,17,24-26], stir bar sorptive extraction (SBSE) [10-12,21-23] and liquid-phase microextraction (LPME) [20,29], have been more recently developed.

Natural springs constituted, for several centuries, the main source of water for the population. A recent study developed by IRAR (Portuguese Regulator Institute for Water and Residues), demonstrated that almost half of the Portuguese population drinks bottled water $(45.3 \%), 37.6 \%$ chooses tap water and a considerable number of people $(16.3 \%)$ drink water from natural springs. The quality of natural spring waters have been coming to be affected by multiple sources of pollution, diffuse or located, constituting, today a public health concern.

This paper presents the optimisation of a solid-phase extraction technique/reverse-phase high performance liquid chromatography-fluorescence 
detection (SPE-HPLC-FLD) methodology, for the determination of five known PAHs in natural spring waters: $\mathrm{BbF}, \mathrm{BkF}$, BghiP, IcdP and BaP.

The performance of the methodology was tested in terms of linearity, limits of detection and quantification, trueness, repeatability and intermediate precision, following the recommendations of the international standard ISO/IEC 17025.

The methodology was then applied to fifty natural springs in villages located in Sintra and Odivelas municipalities, situated in the surroundings of Lisbon. The interest in studying these villages is related with the fact that plenty of natural springs exist in this area and are frequently used by the population.

\section{Materials and methods}

\subsection{Materials}

The PAHs used for the SPE optimization and quantification procedure were: BbF, 99.5\%; BkF, 99.5\%; BghiP, 99.3\%; IcdP 99.5\%; and $\mathrm{BaP}, 98.0 \%$; purchased from Dr. Ehrenstorfer as solid reagents. The PAHs used for the study of the methodology's performance were: $\mathrm{BaP} 100 \mathrm{ng} / \mathrm{uL}$ in cyclohexane, $95 \%$ and IcdP $100 \mathrm{ng} / \mathrm{uL}$ in cyclohexane, 95\%, purchased from Riedel-de-Haen; BkF $10 \mathrm{ng} / \mathrm{uL}$ in acetonitrile, $99.0 \%$, BghiP $10 \mathrm{ng} / \mathrm{uL}$ in acetonitrile, $99.5 \%$ and $\mathrm{BkF}$ $10 \mathrm{ng} /$ in acetonitrilo, $99.5 \%$, purchased from Dr. Ehrenstorfer.

Acetonitrile was HPLC purity from Carlo Erba, n-hexane was Suprasolv grade from Merck and ultra-pure water produced by Milli-Q device from Millipore.

\subsection{Preparation of natural spring water samples}

Fifty natural springs from Sintra and Odivelas municipalities, comprising fifteen villages (Algueirão/Mem-Martins, Belas, Massamá, Queluz, São Martinho, São Pedro, Colares, Montelavar, Almargem do Bispo, Terrugem, São João das Lampas, Caneças, Ramada, Póvoa de Santo Adrião, Odivelas) were analysed.

The samples were collected one time in November/December of 2006, in $1 \mathrm{~L}$ amber glass bottles containing $0.05 \mathrm{mg}$ of sodium sulphite, and were keep under refrigeration $\left(4{ }^{\circ} \mathrm{C}\right)$ and protected from light, until the extraction and subsequent analysis. $250 \mathrm{~mL}$ of the water sample was transferred to $1 \mathrm{~L}$ dark bottle and 75 $\mathrm{mL}$ of acetonitrile was added. All samples were analysed in duplicates, undergoing the SPE-HPLC-FLD procedure. The average value of peak areas was used for the quantification.

\subsection{Chromatographic equipment and experimental conditions}

Identification and quantification of PAHs was done using an Agilent 1100 series HPLC instrument, equipped FLD detector. The separation was performed with a $\mathrm{C}_{18}$ ChromSep HPLC Column SS $25 \mathrm{~cm}$ x 4,6 mm equipped with a ChromSep Guard Column SS 10 x 3 mm (Varian).

The injection volume was $50 \mu \mathrm{L}$ in the low and middle levels and $5 \mu \mathrm{L}$ in high level. The elution temperature was maintained at $30{ }^{\circ} \mathrm{C}$, during 17 minutes running with $100 \%$ acetonitrile. The flow rate was $1 \mathrm{~mL} / \mathrm{min}$. The wavelengths 
chosen for the fluorescence detector were $\lambda_{\mathrm{ex}}=295 \mathrm{~nm}$ and $\lambda_{\mathrm{em}}=420,440$ and $490 \mathrm{~nm}$.

\subsection{SPE equipment and experimental conditions}

A SPE TRACER-Teknokroma vacuum manifold, twelve positions was used. The cartridges $\left(\mathrm{C}_{18}-500 \mathrm{mg} / 6 \mathrm{ml}\right.$ - supplied by Varian) were previously conditioned with $7 \mathrm{~mL}$ of acetonitrile and $14 \mathrm{~mL}$ of ultra-pure water. Aqueous samples were passed through the cartridge at the maximum rate allowed. The glass material was then washed with $20 \mathrm{~mL}$ of acetonitrile/water (30/100) and subsequently passed thought the cartridge. The cartridge was dried by blowing $\mathrm{N}_{2}$ for 20 minutes. Adsorbed PAHs were eluted with $10 \mathrm{~mL}$-hexane and the cartridge was then washed with $2 \mathrm{~mL}$ n-hexane. The solutions were concentrated to 1.0 $\mathrm{mL}$, with $\mathrm{N}_{2}$ blowing, after the addition of $2 \mathrm{~mL}$ acetonitrile.

\subsection{Analytical quantification}

PAHs were quantified by peak area using the external standard method in three working ranges: low, middle and high, injected directly in the HPLC system. In the low range, nine calibration solutions were used for all PAHs (with exception of IcdP - eight points) and ten replicates for each point were prepared. In the middle and high range, nine calibration solutions were used for all PAHs, and ten replicates of the end points were made.

\section{Results and discussions}

\subsection{Optimisation of the SPE procedure}

The SPE technique was selected for the extraction/preconcentration of the PAHs from the water samples. The studies presented by several authors for the extraction of PAHs from water samples, demonstrate that SPE is a technique which presents high recoveries $[3,12,19]$, limits of detection in the sub nanogram per litter level $[1-3,13]$ and it is very easy to implement. It is also a technique suitable for the determination of overall PAHs in water samples [12]. Some literature studies which compare SPE with SBSE [12], SPE with SPME [3] and SPE with LLE [19], demonstrated that SPE is a technique suitable for determination of all PAHs, presenting higher recoveries and limits of detection one order (or more) less.

In the SPE procedure, typical $\mathrm{C}_{18}$ cartridges were used, and the elution volume ( 5 and $10 \mathrm{~mL}$ of $\mathrm{n}$-hexane) and the associated recovery of the PAHs were studied, in two spiking levels.

In the studies presented in the literature, several solvents are used in the SPE procedure for the extraction of PAHs from water samples: n-hexane [3,13], ethyl acetate [1], dichloromethane [3], acetonitrile [3,19] and methanol [2], or combination of two solvents [12]. The solvent n-hexane seems to present the best 
recovery/toxicity combination. Furthermore because n-hexane is the less polar solvent, it is less likely to pull interferences of the cartridges [3].

The average recoveries (R) and relative standard deviation (RSD) obtained for the different elution volumes (V) of n-hexane and spiking levels are presented in Table 1.

Table 1: $\quad$ Recovery (\%) and RSD (\%) for the SPE procedure.

\begin{tabular}{|c|c|c|c|c|c|c|c|c|}
\hline \multirow[b]{3}{*}{ Compound } & \multicolumn{4}{|c|}{ High spiking level } & \multicolumn{4}{|c|}{ Middle spiking level } \\
\hline & \multicolumn{2}{|c|}{$V=5 \mathrm{ml}^{*}$} & \multicolumn{2}{|c|}{$\mathrm{V}=10 \mathrm{ml}^{*}$} & \multicolumn{2}{|c|}{$\mathrm{V}=\mathbf{5} \mathrm{ml}^{*}$} & \multicolumn{2}{|c|}{$\mathrm{V}=10 \mathrm{ml} *$} \\
\hline & $\mathrm{R}(\%)$ & $\begin{array}{c}\text { RSD } \\
(\%)\end{array}$ & R (\%) & $\begin{array}{c}\text { RSD } \\
(\%)\end{array}$ & R (\%) & $\begin{array}{c}\text { RSD } \\
(\%)\end{array}$ & $\mathrm{R}(\%)$ & $\begin{array}{c}\text { RSD } \\
(\%)\end{array}$ \\
\hline $\mathbf{B b F}$ & 85 & 10 & 86 & 11 & 102 & 7 & 100 & 8 \\
\hline BkF & 87 & 6 & 87 & 3 & 100 & 12 & 100 & 9 \\
\hline BghiP & 81 & 4 & 82 & 4 & 100 & 15 & 102 & 15 \\
\hline IcdP & 70 & 9 & 75 & 11 & 86 & 11 & 83 & 18 \\
\hline BaP & 94 & 3 & 91 & 7 & 97 & 10 & 95 & 16 \\
\hline
\end{tabular}

* 6 replicates for each volume analyzed in two days.

There are no significant differences in the R and RSD values, for each level with the two n-hexane volumes. In the high level, $70-94 \%$ recovery was obtained with the $5 \mathrm{~mL}$ volume and $75-91 \%$ with $10 \mathrm{~mL}$ volume. In the middle level, $86-102 \%$ recovery was obtained with the $5 \mathrm{~mL}$ volume and $83-102 \%$ with $10 \mathrm{~mL}$ volume. In both levels, the RSD values obtained were acceptable according to the standards criterion (less than $20 \%$ ).

For the recovery values to be in agreement with the Portuguese legislation $(100 \pm \mathrm{K}, \mathrm{K}$ being accuracy and equal to $25 \%$ ), the $10 \mathrm{~mL}$-hexane volume was chosen for the SPE procedure.

The high recovery values obtained in both levels can be justified by the low water solubility and high hydrophobicity of the compounds (low Henry's constant values $-\mathrm{K}_{\mathrm{H}}$ and high octanol-water partition coefficients $-\mathrm{K}_{\mathrm{ow}}$ ), which explains the high affinity for the organic fraction [1,9]. Comparing the two spiking levels, better values are observed in the middle spiking level, probably due to the better capacity of SPE solid phase to retain low sample amounts.

Analyzing the recoveries values for each $\mathrm{PAH}$, the compound which presents the less value is IcdP, both in the middle and high spiking level. This can be justified by the higher water solubility $(0.062 \mathrm{mg} / \mathrm{L})$ of IcdP, comparing with the other PAHs $\left(2.6 \times 10^{-4}\right.$ to $\left.1.2 \times 10^{-3} \mathrm{mg} / \mathrm{L}\right)$ [9]. The recoveries obtained for all the PAHs are similar to the ones obtained by other SPE techniques $[1,3,13]$.

\subsection{Validation parameters of the analytical methodology}

The analytical parameters evaluated to validate the SPE-HPLC-FLD methodology were: linearity, limits of detection and quantification, trueness, repeatability and intermediate precision.

The linearity of all curves was studied following two steps: 1) adjustment of the working range for a 99\% confidence interval, using the F-test for homogeneity of the variances; 2) calculation of the linearity for each curve 
Table 2: $\quad$ Linearity parameters for the analytical methodology.

\begin{tabular}{ccccccc}
\hline & \multicolumn{3}{c}{ Instrument linearity $\mathbf{( u g} / \mathbf{L})$} & \multicolumn{3}{c}{$\mathbf{R}^{\mathbf{2}}$} \\
\cline { 2 - 7 } Compound & Low range & $\begin{array}{c}\text { Middle } \\
\text { range }\end{array}$ & High range & Low range & $\begin{array}{c}\text { Middle } \\
\text { range }\end{array}$ & $\begin{array}{c}\text { High } \\
\text { range }\end{array}$ \\
\hline BbF & $0.049-0.206$ & $0.10-2.45$ & $2.5-23.0$ & 0.9990 & 0.9997 & 0.9845 \\
BkF & $0.050-0.210$ & $0.10-2.50$ & $2.5-21.8$ & 0.9937 & 0.9878 & 0.9956 \\
BghiP & $0.052-0.220$ & $0.10-2.62$ & $2.6-27.3$ & 0.9976 & 0.9985 & 0,9982 \\
IcdP & $0.076-0.227$ & $0.11-2.70$ & $2.7-28.1$ & 0.9968 & 0.9993 & 0.9977 \\
BaP & $0.048-0.200$ & $0.10-2.38$ & $2.4-24.7$ & 0.9976 & 0.9990 & 0.9958 \\
\hline
\end{tabular}

applying the International Standard ISO 8466-1. Table 2 shows the results obtained for the linearity studies.

A good linear correlation between concentration and peak areas was obtained for all the curves, with correlation coefficients $\left(\mathrm{R}^{2}\right)$ ranging from 0.9845 to 0.9997 and the RSD values less than $8 \%$.

Limits of detection (LOD) and quantification (LOQ) were calculated using two different criterions. The first criterion is based on the determination of the standard deviation of the residuals $\left(\mathrm{S}_{\mathrm{y} / \mathrm{x}}\right)$, obtained from the low range calibration curves. The other is based on the standard deviation $\left(\mathrm{S}_{0}\right)$ of fortified solutions at a sub nano-gram concentration. The results are presented in Table 3.

Table 3: $\quad$ LOD and LOQ for the analytical methodology.

\begin{tabular}{cccccc}
\hline & \multicolumn{2}{c}{ First Criterion } & \multicolumn{2}{c}{ Secon Criterion $(\mathbf{n}=\mathbf{7})$} & LOQ Test $(\mathbf{n}=\mathbf{1 0})$ \\
\cline { 2 - 6 } Compound & LOD* $(\mathrm{ng} / \mathrm{L})$ & LOQ $(\mathrm{ng} / \mathrm{L})$ & LOD $^{* *}(\mathrm{ng} / \mathrm{L})$ & LOQ $(\mathrm{ng} / \mathrm{L})$ & RSD $(\%)$ \\
\hline BbF & 0.02 & 0.07 & 0.29 & 0.87 & 9.9 \\
BkF & 0.05 & 0.16 & 0.25 & 0.75 & 7.9 \\
BghiP & 0.04 & 0.12 & 0.18 & 0.54 & 7.3 \\
IcdP & 0.04 & 0.11 & 0.21 & 0.63 & 14.2 \\
BaP & 0.04 & 0.11 & 0.20 & 0.60 & 8.3 \\
\hline
\end{tabular}

* $\mathrm{LOD}=3.3 \times \mathrm{S}_{\mathrm{y} / \mathrm{x}} . \quad \mathrm{n}-$ number of replicates.

$* * \mathrm{LOD}=\mathrm{AC}_{0}+3.3 \times \mathrm{S}_{0}\left(\mathrm{AC}_{0}-\right.$ average concentration of the fortified solutions $)$.

The limits of detection obtained varied from 0.02 to $0.05 \mathrm{ng} / \mathrm{L}$, using the first criterion, and from 0.18 to $0.29 \mathrm{ng} / \mathrm{L}$, using the second criterion. The second criterion is much stricter, since it considers the entire methodology. These values were later experimentally confirmed, and the RSD values obtained were less than $15 \%$ for all the compounds, indicating that the limits obtained by this criterion were accurately determined.

The LOD and LOQ obtained were similar to those reported by other authors for the determination of PAHs in water samples, using a SPE methodology [13,13-15].

To determine the trueness, repeatability and intermediate precision of this methodology, samples were prepared at a $0.006 \mu \mathrm{g} / \mathrm{L}$ concentration level (ten replicates) in three different matrices, ultra-pure, tap water and bottled water, by 
three analysts. The analytical recoveries $(\mathrm{R})$ were used to evaluate the trueness of the method. The repeatability was calculated as within-day RSD of analyte concentration and intermediate precision was evaluated as RSD of analyte concentration, obtained in consecutive days by three analysts, in different matrices.

Analytical recoveries were acceptable in all the matrices for all the compounds, varying from 80.2 to $110.3 \%$. Comparing the three matrices, $\mathrm{R}$ varying from 94.0 to $110.0 \%$ were obtained for ultra-pure water samples, 95.2 to $110.1 \%$ for bottled water samples and 80.2 to $110.3 \%$ for tap water samples. All these values were satisfactory, leading us to believe that matrices effects can be neglected.

Repeatability and intermediate precision were shown to be adequate, with repeatability RSD values ranging from 4.4 to $13.1 \%$ and intermediate precision RSD values ranging from 5.1 to $13.7 \%$. These results are adequate for water quality monitoring and also very similar to those obtained by other authors for the quantification of PAHs using a SPE-HPLC methodology [3,13-15].

For an external evaluation of the accuracy, the method was tested by participating in an interlaboratory comparison test, organized by Aquacheck. The $\mathrm{z}$-scores ranged from -1.17 to 0.49 , expressing the excellent results obtained by the SPE-HPLC-FLD methodology for the quantification of PAHs in drinking water samples.

\subsection{Analysis of real water samples}

The methodology was applied to real water samples, fifty water springs from Sintra and Odivelas municipalities, comprising fifteen villages.

In the samples analysed, PAHs were detected under the limits proposed by the Portuguese legislation. Nevertheless, in some villages (Massamá, Montelavar, Almargem do Bispo, São João das Lampas, Póvoa de Santo Adrião and Odivelas), low concentrations of PAHs were detected. These results confirmed the need for monitoring PAHs more frequently in these and other natural spring waters.

\section{Conclusions}

In this paper, a highly satisfactory SPE-HPLC-FLD methodology for the simultaneous analysis of five known PAHs in natural spring waters, was presented. The SPE technique showed some advantages in relation to the SPME and LLE extraction techniques, proving to be an easy, simple and low-cost method for extracting PAHs from water samples, with similar or better performance.

The methodology showed good sensitivity, with detection limits two orders of magnitude below the legislation values for PAHs in drinking waters. These values allowed the determination of the proposed compounds at the levels required by the Directive $98 / 83 / \mathrm{EC}$, as it was performed in natural spring waters. 
The results obtained in the validation studies showed that this method is appropriate for the routine analysis of the PAHs in drinking waters, with adequate sensitivity, good linearity, trueness, repeatability and intermediate precision.

In the fifty natural spring samples analysed, the PAHs were detected below the legislation values. The results are encouraging but very few to ensure the quality of natural springs, pointing out the need for monitoring more PAHs in these and other natural spring waters.

\section{References}

[1] Martinez, E., Gros, M., Lacorte, S. \& Barceló, D., Simplified procedures for the analysis of polycyclic aromatic hydrocarbons in water, sediments and mussels. Journal of Chromatography A, 1047, pp. 181-188, 2004.

[2] El-Beqqali, A., Kussak, A. \& Abdel-Rehim, M., Fast and sensitive environmental analysis utilizing microextraction in packed syringe online with gas chromatography-mass spectrometry - Determination of polycyclic aromatic hydrocarbons in water. Journal of Chromatography A, 1114, pp.234-238, 2006.

[3] García-Falcón, M.S., Pérez-Lamela, M. \& Simal-Gándara, J., Comparison of strategies for extraction of high molecular weight polycyclic aromatic hydrocarbons from drinking waters. Journal of Agricultural and Food Chemistry, 52, pp. 6897-6903, 2004.

[4] Chen Wu, H., Wang, Q., Wen Wang, L., I Yang, H., Ahsan, H., Yann Tsai, W., Yu Wang, L., Yuan Chen, S., Jen Chen, C. \& Santella, R.M., Polycyclic aromatic hydrocarbon- and aflatoxin-albumin adducts, hepatitis $\mathrm{B}$ virus infection and hepatocellular carcinoma in Taiwan. Cancer Letters, 252, pp.104-114, 2007.

[5] Farmer, P.B., Singh, R., Kaur, B., Sram, R.J., Binkova, B., Kalina, I., Popov, T.A., Garte, S., Taioli, E., Gabelova, A. \& Cebulsa-Wasilewska, A., Molecular epidemiology studies of carcinogenic environmental pollutants Effects of polycyclic aromatic hydrocarbons (PAHs) in environmental pollution on exogenous and oxidative DNA damage. Mutation Research, 544, pp. 397-402, 2003.

[6] Jamroz, T., Ledakowicz, S., Miller, J.S. \& Sencio, B., Microbiological evaluation of toxicity of three polycyclic aromatic hydrocarbons and their decomposition products formed by advanced oxidation processes. Environmental Toxicology, 18, pp.187-191, 2003.

[7] Charles, G.D., Bartels, M.J., Zacharewski, T.R., Gollapudi, B.B., Freshour, N.L. \& Carney, E.W., Activity of benzo[a]pyrene and its hydroxylated metabolites in an estrogen receptor- $\alpha$ reporter gene assay. Toxicological Sciences, 55, pp. 320-326, 2000.

[8] Van Lipzig, M.M.H., Vermeulen, N.P.E., Gusinu, R. Legler J., Frank, H., Seidel, A. \& Meerman, J.H.N., Formation of estrogenic metabolites of benzo[a]pyrene and chrysene by cytochrome P450 activity and their 
combined and supra-maximal estrogenic activity. Environmental Toxicology and Pharmacology, 19, pp.41-55, 2005.

[9] Wolska, L., Rawa-Adkonis, M., Górecki, T., Zygmunt, B. \& Namiésnik, J., Determination of polycyclic aromatic hydrocarbons and polychlorinated biphenyls in natural waters: problems and challenges. Chemia Analalityczna (Warsaw), 51, pp.35-49, 2006.

[10] García-Falcón, M.S., Cancho-Grande, B. \& Simal-Gándara, J., Stirring bar sorptive extraction in the determination of PAHs in drinking waters. Water Research, 38, pp. 1679-1684, 2004.

[11] Popp, P., Bauer, C., Paschke, A. \& Montero, L., Application of a polysiloxane- based extraction method combined with column liquid chromatography to determine polycyclic aromatic hydrocarbons in environmental samples. Analytica Chimica Acta, 504, pp. 307-312, 2004.

[12] García-Falcón M.S., Pérez-Lamela, C. \& Simal-Gándara, J., Strategies for the extraction of free and bound polycyclic aromatic hydrocarbons in runoff waters rich in organic matter. Analytica Chimica Acta, 508, pp. 177183, 2004.

[13] Urbe, I. \& Ruana, J., Application of solid-phase extraction discs with a glass fiber matrix to fast determination of polycyclic aromatic hydrocarbons in water. Journal of Chromatography A, 778, pp. 337-345, 1997.

[14] Zhou,You-Ya, Yan, Xiu-Ping, Kim,Ki-Nam, Wang, Shan-Wei, \& Liu, Ming-Guang, Exploration of coordination polymer as sorbent for flow injection solid-phase extraction on-line coupled with high-performance liquid chromatography for determination of polycyclic aromatic hydrocarbons in environmental materials. Journal of Chromatography A, 1116, pp.172-178, 2006.

[15] Liu, Jing-fu, Chi, Yu-guang, Jiang, Gui-bin, Tai, C.\& Hu, Jing-tian, Use of cotton as a sorbent for on-line precolumn enrichment of polycyclic aromatic hydrocarbons in waters prior to liquid chromatography. Microchemical Journal, 77, pp.19-22, 2004.

[16] Chen, Hong-Wen, Determination of polycyclic aromatic hydrocarbons in water by solid-phase microextraction and liquid chromatography. Analytical Sciences, 20, pp.1383-1388, 2004.

[17] Cardoso, V.V., Rodrigues, A., Correia, J. \& Benoliel, M.J., Application of SPME in the analysis of polynuclear aromatic hydrocarbons in water by HPLC with DAD detection. Polycyclic Aromatic Compounds, 19, pp.227239, 2000.

[18] Negrão, M.R. \& Alpendurada, M.P., Solvent-free method for the determination of polynuclear aromatic hydrocarbons in waste water by solid- phase microextraction-high-performance liquid chromatography with photodiode-array detection. Journal of Chromatography A, 823, pp. 211$218,1998$.

[19] Titato, G.M. \& Lanças, F.M., Optimization and validation of HPLC-UVDAD and HPLC-APCI-MS methodologies for the determination of selected 
PAHs in water samples. Journal of Chromatography Science, 44, pp. 3540, 2006.

[20] Hou, L. \& Lee, H.K., Application of static and dynamic liquid-phase microextraction in the determination of polycyclic aromatic hydrocarbons. Journal of Chromatography A, 976, pp. 377-385, 2002.

[21] Pettersson, J., Kloskowski, A., Zaniol, C. \& Roeraade, J., Automated highcapacity sorption probe for extraction of organic compounds in aqueous samples followed by gas chromatographic analysis. Journal of Chromatography A, 1033, pp. 339-347, 2004.

[22] León, V.M., Álvarez, B., Cobollo, M.A., Muñoz, S. \& Valor, I., Analysis of 35 priority semivolatile compounds in water by stir bar sorptive extractionthermal desorption-gas chromatography-mass spectrometry, I: Method optimisation. Journal of Chromatography A, 999, pp. 91-101, 2003.

[23] León, V.M., Llorca-Pórcel, J., Alvarez, B., Cobollo, M.A., Muñoz, S. \& Valor, I., Analysis of 35 priority semivolatile compounds in water by stir bar sorptive extraction-thermal desorption-gas chromatographymassspectrometry, part II: Method validation. Analytica Chimica Acta, 558, pp.261-266, 2006.

[24] Doong, Ruey-an, Chang, Sue-min, \& Sun, Yuh-chang, Solid-phase microextraction for determining the distribution of sixteen US Environmental Protection Agency polycyclic aromatic hydrocarbons in water samples. Journal of Chromatography A, 879, pp. 177-188, 2000.

[25] Djozan, Dj. \& Assadi, Y., Monitoring of polycyclic aromatic hydrocarbons in water using headspace solid-phase microextraction and capillary gas chromatography. Microchemical Journal, 63, pp.276-284, 1999.

[26] Liu, Yu, \& Lee, M.L., Solid-phase microextraction of PAHs from aqueous samples using fibers coated with HPLC chemically bonded silica stationary phases. Analytical Chemistry, 69, pp.5001-5005, 1997.

[27] Manodori, L., Gambaro, A., Piazza, R., Ferrari, S., Stortini, A.M., Moret,I. $\&$ Capodaglio, G., PCBs and PAHs in sea-surface microlayer and subsurface water samples of the Venice Lagoon (Italy). Marine Pollution Bulletin, 52, pp.184-192, 2006.

[28] Anyakora, C., Ogbeche, A., Palmer, P. \& Coker, H., Determination of polynuclear aromatic hydrocarbons in marine samples of Siokolo Fishing Settlement. Journal of Chromatography A, 1073, pp. 323-330, 2005.

[29] Rezaee, M., Assadi, Y., Hosseini, Mohammad-Reza M., Aghaee, E., Ahmadi, F. \& Berijani, S., Determination of organic compounds in water using dispersive liquid-liquid microextraction. Journal of Chromatography A, 1116, pp.1-9, 2006. 